\title{
Cartógrafo do corpo e do espírito
}

DoI

http://dx.doi.org/10.11606/ 2179-0892.ra.2018.148930

\section{Tradução}

Maria Victoria Gaburro de Zorzi e Fernanda Arêas Peixoto Universidade de São Paulo | São Paulo, SP, Brasil victoriadezorzi@yahoo.fr, fareaspeixoto@gmail.com
RESUMO

O texto retoma a experiência da autora como aluna e orientanda de Michel de Certeau na Paris da década de 1970, tocada pela efervescência política do maio de 68. Apresentam-se reflexões sobre a importância do professor, tanto de suas análises teóricas, quanto de seu espírito livre e anticonvencional, bem como ponderações sobre sua formação e sobre o feitio de sua antropologia.
PALAVRAS-CHAVE

Maio de 68, cursos de Michel de Certeau, cidade e cultura plural, Antropologia dos cinco sentidos 
Sobretudo (trata-se de um corolário, masé importante aqui), a análise fenomenológica e praxeológica das trajetórias culturais deve permitir a preender, ao mesmo tempo, uma composição de lugares e a inovação que a modifica ao a travessá-las. Michel de Certeau, Cultura no plural (2005: 251)

Nos anos de 1976 e 1977, Michel de Certeau lecionava na Universidade de Paris 7 , conhecida como Jussieu devido ao nome da praça na qual fora construída, após maio de 68, próxima ao Sena. Sua arquitetura composta por cerca de cinquenta torres, ligadas por prédios suspensos sobre uma esplanada sempre exposta às correntes de ar, tinha por objetivo fazer com que os estudantes circulassem, em vez de se reunirem para contestar. Isso não impediu que, durante os anos 70, a Paris 7 fosse um importante centro de encontro dos autonomes ${ }^{2}$ que, com lenço vermelho ou keffieh palestino preto e branco, agrupavam-se nas escadarias da entrada (hoje inacessíveis) por ocasião das manifestações de Paris. No departamento de etnologia, outra contestação mobilizava professores e alunos. Ela fora criada por Robert Jaulin, então em conflito com Lévi-Strauss, crítico ao seu apoio à sociedade contra o Estado de Pierre Clastres ou à sua denúncia pública do etnocídio na Amazônia (Jaulin, 1974). Ceorges Condominas, signatário como Jaulin do manifesto dos 121, Declaração sobre o direito à insubmissão na guerra da Argélia, havia inventado o conceito de etnocídio a partir do convívio com os Mnong Gar, povos do Vietnã, dos quais ele nos falava entre suas viagens. Os marxistas da Paris 7 alertavam contra a antropologia, que nutrira impérios coloniais como a França, e o rico material de Condominas, nascido no Vietnã, teria permitido, a seu despeito, capturar os combatentes da Indochina. Nos encontrávamos toma-
1 Acerca do título "Cartógrafo do corpo e do espírito": no original, arpenteur (du corps et de l'esprit) possui um duplo sentido,o técnico-agrimensor-e o caminhante (N.T.).

2 O movimento dos autonomes, na França, corresponde a uma corrente de extrema esquerda, de inclinação anarquista, oriunda dos movimentos de maio de 1968. Eram conhecidos por suas práticas baseadas nas ações diretas, acompanhadas, em geral, do uso da violência (N.T.). 
dos por questões políticas e éticas, as discussões pipocando entre professores e público, por todos os corredores do departamento de Jussieu.

Na universidade, estávamos matriculados não tanto para obter um diploma, mas sobretudo para mergulhar nesse fórum, algo raro e viciante. Jean Monod, autor de Barjots ([1968] 1971) - uma pesquisa sobre grupos da periferia de Paris encomendada pela revista Elle - voltava dos Piaroa da Venezuela falando de visões xamânicas, de poesia e de suas experiências alucinatórias, permanecendo às vezes em silêncio para nos fazer sentir os espíritos. Jean-Toussin Dessanati, filósofo da matemática, ensinava que precisávamos dela para compreender a complexidade dos sistemas de parentesco dos povos sem escrita, e que a matemática podia ser fonte de fruições metafísicas. Dominique Temple dizia ser preciso utilizar a lógica da contradição de Lupasco para dar conta da lógica da reciprocidade ameríndia, contra a lógica da identidade que impelia o Ocidente à exclusão. Muito antes da metafísica canibal de Viveiros de Castro, nos bancos escolares da Paris 7, éramos incitados a nos descentrar para pensar as relações entre o quântico e o psíquico das quais os indígenas teriam a chave, tanto ou mais que os cientistas. Na psicanálise, Daniel Sibony especulava sobre as diversas formas de alteridade que atravessam o inconsciente, enquanto Jean Arlaud, cineasta, fazia-nos descobrir aquelas que emergiam dos filmes etnográficos provenientes de todo o mundo. Robert Jaulin convidava regularmente indígenas que nos contavam de suas lutas. Judith Brown chegara da Califórnia para falar dos "Women Studies", que iriam rapidamente abrir o campo feminista dos Cender Studies, e também das lutas anticapitalistas das ecofeministas, como Starhawk.

Os cursos de Michel de Certeau estavam imersos nessa atmosfera. Tivemos muita sorte em conseguir um lugar no seminário deste que se tornaria um dos cofundadores da escola lacaniana, enquanto, algumas ruas adiante, centenas de pessoas permaneciam na porta do salão em que ocorria o seminário de Lacan. Lacan era abordado nos cursos de Certeau, mas os assuntos principais eram a mística e as flâneries pela cidade. Um jesuíta, considerado por muitos na época como distante da ordem religiosa (jésuite défroqué) ${ }^{3}$, era ao mesmo tempo psicanalista e historiador, e falava da cidade de uma perspectiva etnológica. Certeau era valioso em um momento no qual alguns antropólogos clássicos postulavam que os cultos afro-brasileiros e as culturas ultramarinas da Reunião ou das AntiIhas colonizadas pela França seriam "aculturadas", excessivamente misturadas para serem culturalmente autênticas e, por isso mesmo, indignas de interesse dos verdadeiros estudos etnológicos. Tive a sorte de ser formada no lugar mesmo onde desconstruíamos tais preconceitos - que ainda persistem entre alguns antropólogos na França, no Brasil e em diversos lugares.

Ouvi o termo "etnologia" pela primeira vez no rádio, escutando justamente 
uma entrevista de Chambard de Lauwe, que falava da cidade. Eu morava na cidade e era a cidade, como espaço de cultura em vias de fabricação, que eu queria compreender, a partir de meios heterogêneos e híbridos. Era isso que Michel de Certeau nos ajudava a pensar, antes mesmo da publicação de seus livros sobre A invenção do cotidiano (1980) e de sua prática da cidade. Em A cultura no plural ([1974] 2001), ele antecipava as questões dos Cultural Studies e os problemas do multiculturalismo, como destacou Richard Terdiman, da Universidade da Califórnia em Santa Cruz, na $4^{\text {a }}$ edição da tradução inglesa do livro (Culture in the Plural, 2001). Acima de tudo, seus cursos convidavam a uma flânerie no espaço urbano em direção a um outro mundo, entre loucura e mística.

Em seu curso de 1976 na Paris 7, Michel de Certeau nos fez trabalhar sobre "Mélancolique et/ou mystique: ].-J. Surin. Fable du nom et mystique du sujet: Surin"4. Surin foi um místico do século XVII, nascido em Bordeaux em 1600, em uma família de comerciantes, que se tornou nobre. Morto em 1665, ele foi autor de La Science expérimentale. Na cópia que guardei, eu havia destacado em rosa, na parte intitulada "O significante, ou o corpo desmedido", as seguintes palavras aqui sublinhadas:

Oobjeto apreendido em uma rede de amor torna-se subitamente um Observador que, do fundo do quadro, como em algumas pinturas, ol ha de cima o espectador transformando-o em um ser observado 5 com furor.

Como o mundo de Júlio Verne (em A viagem ao centro da terra), o corpo éoco. É uma caverna, ocupada por estes "lagos do ventre" (Groddeck). O corpo inteiro é uma "boca". Daí essas praias interiores, que "beijam", por meio de deliciosas ondas, as orlas do outro. (Nota 27 bis: Mais tarde, Surin falará da mesma forma sobre a "paz" após os sofrimentos (...). O mar em sua plenitude vem visitar a terra e beija as margens que Deus Ihes deu como limite) (Surin apud Certeau, 1978: 41) .

Não há saber senão o erótico - pela alteração a terrorizante ou deliciosa que transforma o corpo em um terreno irreconhecível, ilegivel pela intervenção do desconhecido (idem: 42).

"O estudo da mística permite (então) uma exegese não religiosa da religião", escreveu de Certeau em l'Encyclopédie universalis (1968: 526). Foi ele, então, que eu escolhi para orientar a minha dissertação de mestrado intitulada Antropologia dos cinco sentidos. Ele se divertiu muito com o texto final que eu entreguei em seu apartamento, na Rua de Lourmel. Ao longo das 65 páginas do texto, decidi substituir a maior parte das marcas de pontuação por reticências. A dissertação começava pelo que denominei de meu "mito pessoal", a partir do meu uso da visão, da audição, do olfato, do paladar e do tato e, em seguida, desdobrava-se através de mitos recolhidos mundo afora (na Biblioteca Nacional da França e na
4 A primeira nota do texto de Certeau sobre Surin esclarecia que este texto fora retomado de uma apresentação em um seminário organizado por Julia Kristeva no hospital da Cidade Universitária e dá sequência a "L'Énonciation mystique" (Certeau, 1976). "Mélancolique et/ou mystique J.J. Surin" (Certeau, 1978) é citado como pouco conhecido por Claude Rabant (2002)

5 Em destaque no texto de Michel de Certeau sobre Surin (1978: 40, nota 23). As referências também são dele no mesmo texto: Lacan 1973. Le Séminaire, livre XI Les Quatre concepts fondamentaux de la psychanalyse. Paris, Seuil; Merleau-Ponty. 1964. Le Visible et l'invisible. Paris, Gallimard.

6 Certeau refere-se ao texto de J.J. Surin, "Questions importantes à la vie spirituelle sur l'Amour de Dieu", III, 2, Téqui, 1930, p. 116-117. 
Biblioteca Ste. Geneviève), para interrogar cada um dos cinco sentidos, particularmente em relação à dor e ao prazer. O conjunto estruturava-se por certa busca do sagrado, que atravessa o corpo em movimento. Tendo começado com as querelas entre os empiristas ou sensualistas e os racionalistas ou idealistas, terminava com uma apologia dos aprendizes de feiticeiros... (Ver as duas imagens).

Inspirada, entre outras, por antigas leituras que mencionavam serem as viúvas aborígenes da Austrália submetidas, durante dois anos, a um tabu em relação à palavra, decidi viajar para lá em 1979. Eu me encontrava em busca tanto de uma comunicação que excluísse o significante, quanto de uma feminilidade oriunda de atividades realizadas somente entre mulheres. Assim, realizei minha pesquisa de campo com os Warlpiri do deserto central, onde as mulheres se encarregaram de mim, impulsionando minha vida em direção a um desconhecido, que continuo a descobrir, a cada dia, inclusive no Brasil, graças à umbanda (Clowczewski, 2015). Durante a minha primeira estada australiana, fui a Canberra para tentar obter uma bolsa do Instituto de Estudos Aborígenes (IAS, que se tornou AIATSIS). Peter Ucko, então seu diretor, fez diversas perguntas sobre minhas leituras e concluiu que o departamento da Paris 7 não dava boa uma formação em antropologia, pois nós rejeitávamos o estruturalismo de Lévi-Strauss, sem ao menos ensinar Radcliffe-Brown e outros ancestrais incontornáveis... Consequentemente, eu não podia receber o financiamento para pesquisa do instituto...

Escrevi imediatamente a Michel de Certeau para falar de minha decepção e mesmo para responsabilizá-lo um pouco por essa situação ${ }^{7}$... Quatro anos mais tarde, enviava a ele um exemplar de La Cité des cataphiles. Mission anthropologique dans les souterrains de Paris (Clowczewski, 1983), livro prefaciado por Félix Cuattari, resultado de uma pesquisa que eu realizara sobre os andarilhos clandestinos das galerias subterrâneas de minha cidade. Fiquei muito triste por ter esse cartógrafo da cidade e da cultura plural nos deixado antes mesmo que eu pudesse lhe oferecer Les Rêveurs du désert (Clowczewski, [1989] 1996). Esse trabalho dedicava-se a andarilhos que ele certamente teria compreendido melhor que Durkheim (Clowczewski, 2014) em função de sua relação com a caminhada, com a nominação da topografia, com a ajuda de uma filosofia do desejo, os Dreamings em devir. De fato, os Warlpiri da Austrália central fabricam uma espiritualidade que os antropólogos chamam de totêmica, mas que eles designam como Sonhos (Jukurrpa, Dreaming), redes de caminhos que ligam os lugares sagrados por meio de relatos míticos e cantos rituais, cartografados em pinturas corporais e danças. Foi escrevendo esse livro que eu compreendi a que ponto minha formação na Paris 7, na qual Michel de Certeau foi um fermento, permitiu-me perceber o campo australiano de forma distinta, o que me levou a fazer outra etnologia e antropologia, diferente daquela que, desde então, critico sistematicamente.

"É necessário um sexto sentido, pelo qual o sujeito se volte para si mesmo 
e o corpo para o corpo, sentido comum ou sentido interno", escreverá, em 1985, Michel Serres (1985: 52), que observava como a palavra randonnée (caminhada) vem do francês antigo randon (corrida veloz e impetuosa), que em inglês deu origem a random (aleatório). Deligny também falava de um sexto sentido, que ele atribuía ao tempo, cartografando durante toda a sua vida as linhas de errância de crianças autistas que, em seu acampamento das Cévennes, caminhavam randomly, mas não completamente. Deligny é, portanto, outro cúmplice de Guattari e Deleuze, que em "As crianças que falam" de Critique et clinique (1993) sobrepuseram as trajetórias das crianças autistas àquelas dos aborígenes, para quem o imaginário e o real são duas faces do virtual e do atual ${ }^{8}$. Eu havia lido alguns textos de Deligny, o caçador fora da linguagem, e assistira ao seu filme $\mathrm{Ce}$ Gamin là antes de partir para o campo australiano. Foi necessário al gum tempo para que tais ideias, que nos encantavam nos escritos, nas salas de projeção e nos debates após 1968, encontrassem ressonância em diversos cientistas, que mostraram a existência de um sexto sentido sinestésico e magnético, essencial não apenas para os homens, mas também para os pássaros ou para as plantas ${ }^{10}$.

Michel de Certeau foi um visionário do sexto sentido por sua mística encanta$\mathrm{da}$, incorporada um pouco à maneira dos encantados dos cultos brasileiros. Foi com o passar do tempo que eu compreendi aquilo que ele, assim como Cuattari, seu cúmplice em psicanálise e lutas micropolíticas ${ }^{11}$, e alguns outros, haviam impregnado em mim quando, desde meus 18 anos, eu bricolava filmes experimentais para sair da linguagem e ultrapassar os limiares sensoriais (Clowczewski, 2012 e 2017).

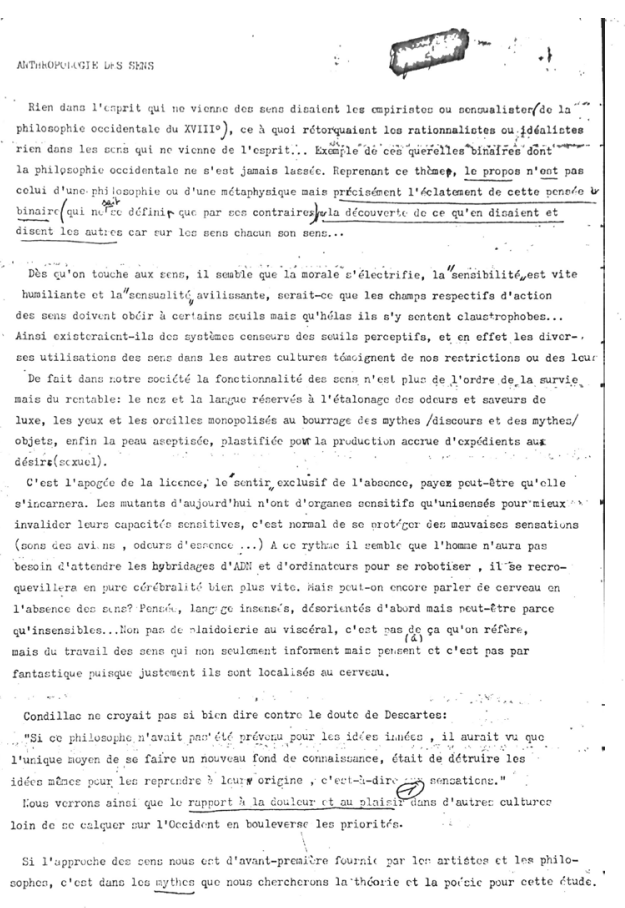

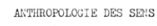

Si je devais reprendre ce travail à zéro aujourd'hự, je ne partirais plus de nythes pour prétandre cerner 1'apprehensiton sensorielle d'autres cul tures mais do fillag dit to

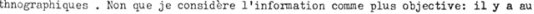
de subjectivité dans 1a transeription vis suelle du comportenent des gene qu'il peut y en avoir dane oele éerite et l'interprótatation d'un uy the. Hais c'est que arrivée ou bout

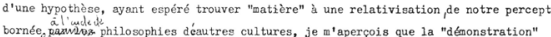
est métaphysique alors que je prétendais y y échapper... tout au long de ce parcour

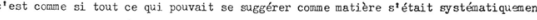
evaporé satisfaia sant au principe de nét zaorphihoses perranentes que j'évoquais tout le long: J'ai été prise à mon propre piège... il reete do garder de ce texte la sennation d'un voyege pas plus physique que métaphysique mais alchimi que... c'est une jouis ssance que je ne regrette pas bien qu' elle relève déjà de l'ordre d'un vieux rêve (ce ue pas la prenoritition:), 10 pasoo dos autros peut encore estre notre futur...

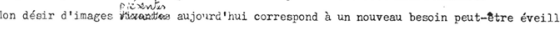

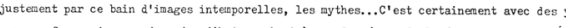
yeux neufs que je regerde aujourd' hui un abori iène qui prepare de la farine, un peul m.

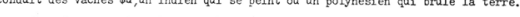

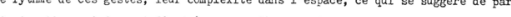

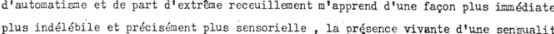
plus indélébilie et précíiéent plus sensorielle, , la présence vivante d'une sensuali

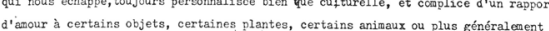

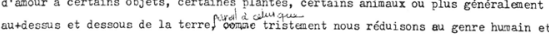
autdessus

'al partors lingression que La magie o' est se surprendre de voir quel que chose que nous ne vojions pas dans ce que nous reezarcions, lentendre quelque chose que ncus n'entendions pas dans ce que nous écoutions, tescentir the odeur là où nous prétendions qu'il n'y en avait pas, d'etre en extase en mangeant du chococat ou de ne plus sentir a liwite de jointure entre sa peau et ce que 1 'on touc he... Nous pourrions tous

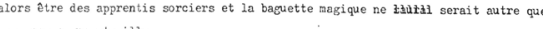
nos gens en un et mille.
8 Ver Clowczewski (1991).

9 Ver comunicação feita no Colóquio Deligny, UER], agosto de 2016, "Devenir trace Des Lignes d'erre aux lignes de chants aborigènes" (disponível em: https://cadernosdeligny. jur.puc-rio.br/index.php/ CadernosDeligny/article/ view/14, acesso em 12 de julho de 2018). No original, "le pisteur hors du language" refere-se àquele que persegue pistas, como numa caçada (N.T.).

10 Para Jean-Pierre Roll e Régine Roll, o cérebro se alimenta da atividade sensorial que ele mesmo gere através dos seus comandos e dos quais ele memoriza os efeitos. Por atividade sensorial, eles entendem aquela dos cinco sentidos, mas descrevem também um sexto sentido, o sentido muscular. Os músculos "garantem uma 'verdadeira visão interior', fonte mesmo do conhecimento do corpo" (1996: 73), "o fundamento de todo conhecimento resulta de uma apropriação ativa do ambiente pelos diferentes órgãos do sentido, que adquirem movimento graças às deformações e deslocamentos do corpo" (1996: 78-79). Corpo e espírito seriam, então, interdependentes. Pesquisadores do laboratório de Fisiologia celular e molecular das plantas (Universidade Paris VI / CNRS) em colaboração com equipes alemãs das universidades de Marbourg e de Frankfurt, por sua vez, mostraram que "todos os organismos biológicos são dotados de um sexto sentido: aquele capaz de perceber os campos magnéticos" “"Le 'Sixième sens' des plantes", Communiqués de presse, 2006, disponível em: http://www2. cnrs.fr/presse/communique/925 htm, acesso em 12 de julho de 2018);.ver também Antonio Damasio ([1994] 2006). 
Barbara Clowczewski é pesquisadora do CNRS (directeur de recherches) e do Laboratoire d'Anthropologie Social (LAS/Collège de France). Autora de diversas obras, entre as quais, Les Rêveurs du desert (1989), Du Rêve à la loi chez les Aborigènes. Mythes rites et organisation sociale en Australie (1991) e Devires totêmicos (2015).

11 Ben Highmore assinala alguns pontos comuns com Guattari, principalmente $\mathrm{o}$ apoio às rádios livres e o entusiasmo de Certeau em relação à clínica de La Borde, onde Guattari trabalhava (Highmore, 2006:79).

\section{REFERÊNCIAS BIBLIOCRÁFICAS}

AHMAD, Margaret etal.

2006 "Magnetic Intensity Affects Cryptochrome-Dependent Responses in Arabidopsis thaliana". Planta, 225 (3): 615-624.

CERTEAU, Michel de

1968 "Mystique". Encyclopaedia Universalis, XI: 521-526.

[1974] 2001 Culture in the Plural. Minneapolis, University of Minnesota Press. ( $2^{\mathrm{a}}$ ed. francesa, 1980; ed. bras., 2005).

1976 "L'Énonciation mystique". Recherches de Sciences Religieuses, t. 64: 183-215.

1978 "Mélancolique et/ou mystique: J.-J. Surin. Fable du nom et mystique du sujet: Surin". Analytiques, n. 2: 35-48.

1980 L'Invention du quotidien, 1. Arts de faire. 2. Habiter, cuisinier. Paris, UCE, colle. 10-18 (2 vols).

CUSSET, François

2006 La Décennie. Le Grand cauchemar des années 1980. Paris, La Découverte.

DAMASIO, Antonio

[1994] 2006 L'Erreur de Descartes. La Raison desémotions. Paris, Odile Jacob.

DOSSE, François

2002 Michel de Certeau. Le Marcheur blessé. Paris, La Découverte.

DELEUZE, Gilles e GUATARRI, Félix

1993 Critique et clinique. Paris, Éditions de Minuit.

CLOWCZEWSKI, Barbara

1983 (et al.) La Cité des cataphiles. Mission anthropologique dans les souterrains de Paris. Paris, Librarie des Méridiens (reimpressão aumentada de 60 páginas, Éditions ACP, 2008). Disponível em: http://www.acp-asso.org/citedescataphiles.php, acesso em 12 de julho de 2018. 
[1989] 1996 Les Rêveurs du désert, Les Warlpiri. Édition de poche avec nouvelle postface, Actes Sud, Babel [nova edição 2017].

1991 Du Rêve à la loi chez les Aborigènes. Mythes rites et organisation sociale en Australie. Paris, PUF.

2004 Rêves en colère. Avec les Aborigènes australiens, Paris, Plon, Terre Humaine.

2014 "Rejouer les savoirs anthropologiques: De Durkheim aux Aborigènes". Horizontes Antropológicos, 41: 381-403.

2012 "Collures: Du Cinéma expérimental à l'anthropologie". L'Unebévue $n^{\circ}$ 30: Aujourd`hui, Dieu csest nous, 30: 203-214.

2015 Devires totêmicos. Cosmopolítica do sonho. São Paulo, n-1 edições.

2017 "Cosmocores - performance fílmica de incorporações no Brasil e conversa com a Preta Velha Vó Cirina". GIS-gesto, imagem e som, v. 2, n. 1: 277-301. Disponível em: http://dx.doi. org/10.11606/issn.2525-3123.gis.2017.129204, acesso em 12 de julho de 2018.

HICHMORE, Ben

2006 Michel de Certeau: Analysing Culture. Londres, Bloomsbury Publishers.

JAULIN, Robert

1974 La Décivilisation. Bruxelas, Éditions Complexes.

MONOD, Jean

[1968] 1971 Les Barjots. Essais d'ethnologie des bandes des jeunes. Paris, UCE, col.10-18.

RABANT, Claude

2002 "Michel de Certeau, lecteur de Freud et Lacan". Espace Temps, número temático "Michel de Certeau, histoire/ psychanalise", vol. 80, n. 1: 22-26.

ROLL, Jean-Pierre e ROLL, Régine

1996 "Le sixième sens". Science et Vie, Paris, Excelsior Publications S.A., n. 195: 70-79. Disponível em: https://sciences.univ-amu.fr/sites/sciences.univamu.fr/files/lesixiemesens.pdf, acesso em 12 de julho de 2018.

SERRES, Michel

1985 Les Cinq sens. Paris, Éditions Grasset.

Recebido em 7 de dezembro de 2017. Aceito em 16 de junho de 2018. 